\title{
Notes on personal names and abbreviations in late Arsinoite and Heracleopolite documents
}

The papyri discussed in this article date from the seventh and especially eighth centuries, and all but two or three are Arsinoite. The bulk consists of fiscal documents, where the use of abbreviation is the norm, a feature that occasionally obscures reading and interpretation. The collection of notes below addresses textual difficulties caused by abbreviations. $\left({ }^{1}\right)$

\section{P.Rain. Unterricht 55}

$\Phi 1 \lambda \circ \delta(\eta \operatorname{\eta n} \mu v)$ occurs in 1.3 of this writing exercise, but it is surprising to find this name in a text of late date from the Fayum. The scholasticus $\Phi$ i $\lambda$ ó $\delta \mu \circ$ o in SB XVIII 13949.4 (Oxy.; 541) is an isolated figure in our evidence from late antique Egypt. The dotted $\delta$ indicates reservations; the reading is conceivable, but not inescapable:

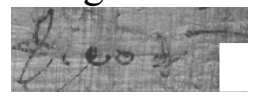

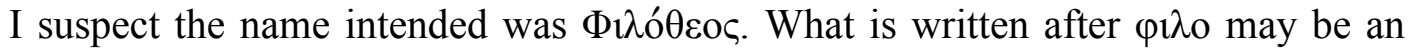
inept rendering of the compendium representing $\theta \varepsilon$; it may also be relevant that the top of the letter is not tilted backwards as in other deltas in this hand, and resembles the form of $\theta$ in combination with $\varepsilon$ in texts of this period. Alternatively, it could be a phonetic spelling, with $\delta$ written instead of $\theta$; I have not found any other instance of * $\Phi \uparrow \lambda o ́ \delta \varepsilon \circ \varsigma$, but there are several examples of names beginning $\Theta \varepsilon o-$ written as $\Delta \varepsilon 0-$ (cf. below, nos. 21 and 23).

\section{P.Ross.Georg. V 73}

The juxtaposition of Arabic and Greek toponyms in this document of the late eighth century has made it a minor celebrity. An image appeared recently on line, and allows for some textual progress to be made in spite of its very low resolution.

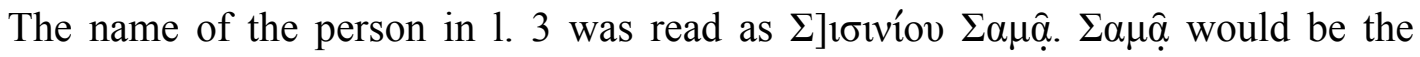
genitive of a name not attested elsewhere, but it seems to me possible to read $\Sigma \alpha \mu \beta(\hat{\alpha})$ (or $\Sigma \alpha \mu \beta \hat{\alpha}$ ). Perhaps this person recurs in $S P P$ X $42.2 \Sigma 1] \sigma ı v i ́ o v ~ \Sigma \alpha \mu \beta \hat{\alpha}$.

The curious $\pi \tau \rho \circ \beta \varepsilon($ ) comes up in 1. 10; the papyrus has $\pi \rho \circ \beta$, topped by the sign that usually indicates abbreviation after $\varepsilon$, so that the editor's $\varepsilon()$ is the expected rendering. However, $\varepsilon$ leads nowhere; with $\pi \rho \circ \beta$ preceding, we expect $\alpha$. This would suggest $\pi \rho \circ \beta(\alpha \tau \circ \theta 0$ iov), as in SPP X 229.7 (abbreviated, but the expansion seems

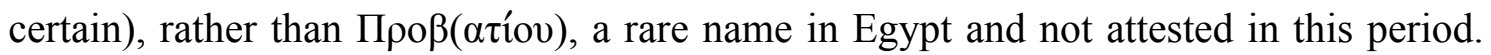

(*) I am grateful to Federico Morelli for a critical reading of many of these notes, and to Alain Delattre and Naïm Vanthieghem for some useful suggestions.

(1) The new readings proposed in this article are based on images accessible through $<$ www.papyri.info $>$ and <https://search.onb.ac.at/primo-explore/search?vid=ONB\&sortby=rank\&lang= de_DE $>$. The image clippings are (C) Österreichische Nationalbibliothek, Papyrussammlung.

$\bar{N}$ ote on transcriptions. I have sometimes used a superscript stroke to represent abbreviations, but this is only an indicative approximation. In several cases it is clear that $\alpha$ or $\varepsilon$ were intended, but in a few others the form of the abbreviation stroke would allow either; for this reason, I have systematically placed $\alpha$ or $\varepsilon$ inside the parentheses. Another issue is the rendering of superscript ov, often in the form of raised ' $v$ '; I consider this a simplification of the monogram and have given it as unabbreviated ov. 
The use of the same abbreviation stroke for $\alpha$ and $\varepsilon$ occurs in a number of documents of

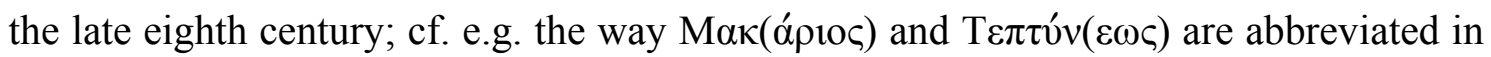
$S P P$ X 80.6; cf. also below, nos. 6 (SPP XX 249v.iii.2) and 13. $\left(^{2}\right)$

\section{P.Wisc. II 45}

The papyrus preserves a list of payments assignable to the eighth century. Certain names strongly point to the Fayum or environs as the document's origin. The text has been improved substantially since its publication, $\left({ }^{3}\right)$ but some uncertain readings remain, one of them in $1.2, \Phi . \lambda \tau \alpha()$ :

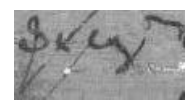

I propose to read $\Phi \mathbf{i} \lambda \underline{\theta} \theta\left(\varepsilon_{\text {ovo }}\right)$, with o $\theta$ squeezed together.

\section{SB XVI 12253}

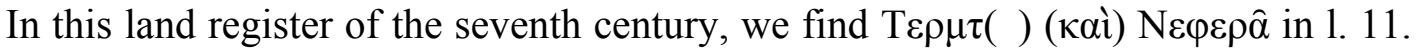
The editor wrote: "wenn es sich nicht um interne Abkürzung handelt, ist der Name noch nicht bekannt" (Aegyptus 61 [1981] 91). This is indeed an abbreviation $\left({ }^{4}\right)\left(\tau \varepsilon \rho \mu^{\tau}\right.$ pap.)

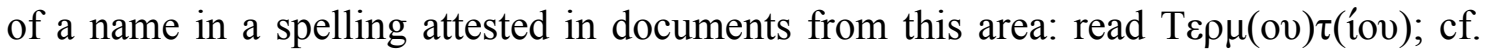

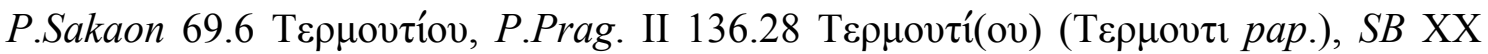

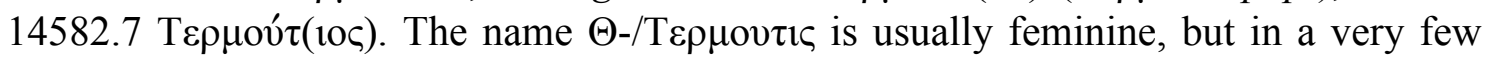
cases the bearer is or could be male.

\section{5. $S B \times X 14582$}

The first name in 1.5 of this list of names of the seventh/eighth century was read as $\alpha \prime \pi(\alpha) \Pi \alpha \kappa v(\sigma 10 \varsigma)$. It would be unusual to find $\alpha \pi \alpha$ abbreviated; the published photograph (Pap.Flor. XIX.2, Tav. XLII) shows that the top of $\pi$ has the form of an oblique rising from the left to the right and reaching above the line:

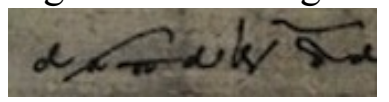

This might be a convention of writing double pi; we find something similar with double theta and double tau in a text of $612 .\left(^{5}\right) \mathrm{N}$. Vanthieghem also points to a similar form of pi in P. Vindob. K 44. I propose to read 'A $\pi \pi \alpha \kappa \hat{v}(\rho \circ \varsigma)$; the spelling of the name with double $\pi$ is fairly common.

(2) Even though $\varepsilon($ ) would appear to be the more natural reading, the problem of $M \varepsilon \lambda \varepsilon($ ) in P.CtYBR inv. 461.8 (see BASP 53 [2016] 208, 218) would disappear if we read $\alpha$ instead of $\varepsilon$ : Mé $\lambda \alpha($ ), that is, $\operatorname{M\varepsilon ́} \lambda \alpha(\varsigma)$ or $\operatorname{Mé} \lambda \alpha($ vo $)$.

(3) Various corrections are recorded in $B L$ VII 281 and XII 290. The latter goes back to my note in $Z P E$ 136 (2001) $121 \mathrm{n}$. 12, but $B L$ does not record the starting point of the discussion, that the dots in the

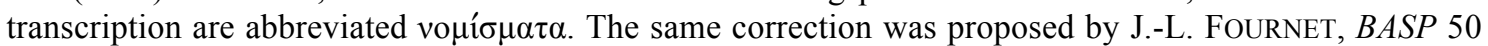
(2013) 300, with reference to the text given by H. HARRAUER, Handbuch der griechischen Paläographie. Textband (Stuttgart 2010) 501, no. 296. The latter version incorporates corrections from BL VII 281, adds

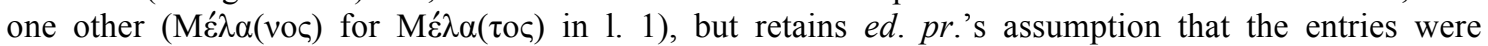
intended to be in the nominative (genitives in $B L$ VII 281).

(4) J. DieThART, Prosopographia Arsinoitica I (Wien 1980) 367, n. 601, proposed 'Z.B. als unbelegtes

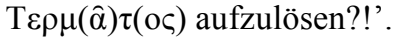

(5) See P.Gascou 32 introd., p. 175. 


\section{SB XXII 15244, etc.}

The text is another list of names; it was assigned to the seventh century, but probably belongs to the early eighth. The first extant entry refers to 'A $\mu \omega v$ víov a $\sigma \tau$ ov $\beta o \eta \theta($ ov̂) (i.1). The presence of an $\alpha \sigma \tau$ ó $\varsigma$ in a text of this date is implausible. The online image reveals that the papyrus has 'A $\beta \omega v(\hat{\alpha})$ 'Iov́ $\sigma \tau o v$ :

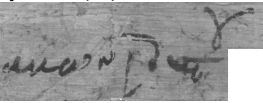

The name 'A $\beta \omega v \alpha \hat{\alpha}$, has occurred in a few other Arsinoite texts of this period, but this was not always recognized in their first edition. Thus 'A $\omega v($ ) was read in P.Rain. Unterr. 80.i.3, but the reproduction shows that the papyrus has ' $A \beta \omega v(\hat{\alpha})$. There is a similar problem in SPP X 172.2: ed. pr.'s 'A $\omega \omega v \varepsilon($ ) was corrected to 'A $\beta \hat{\omega} v$ (BL VIII $458)$, but there too we should read $A \beta \omega v(\hat{\alpha})$, to account for the superscript stroke. The more straightforward instances include SPP XX 175.1, and 242.8, 32, 70.

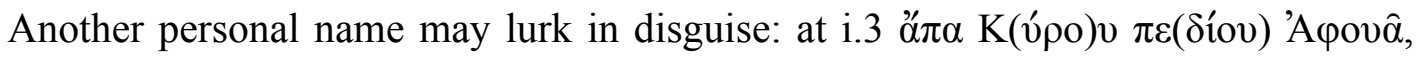
and ii.3, $\Gamma \varepsilon \omega \rho(\gamma$ íov) $\pi \varepsilon(\delta i ́ o v)$ 'A $\varphi$ ovâ; it would be easier to reckon with a name rather than (a phonetic version of) $\pi \alpha 1 \delta$ íov. The abbreviation is drastic, which suggests a

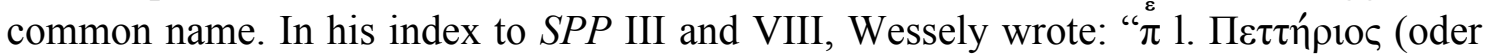

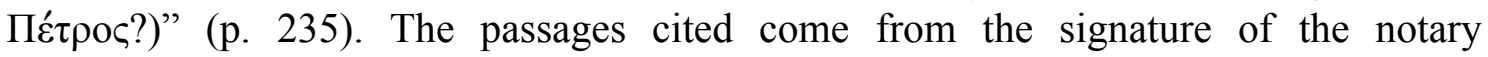

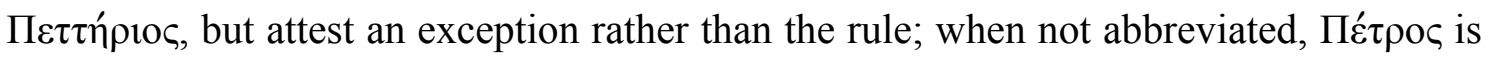
much better represented in our evidence. Faced with a similar abbreviation, the editor of

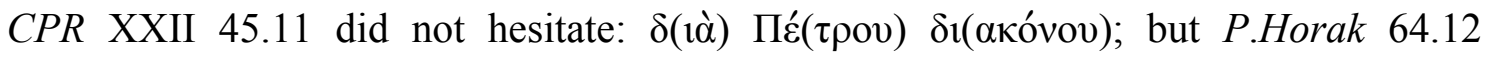
$\Theta \varepsilon o ́ \delta(\omega \rho \circ \varsigma) \Pi \frac{\varepsilon}{(\tau \rho \rho v)}$ indicates reservations. In a similar vein, in SPP XX 249v.iii.2

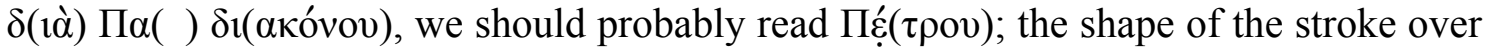
$\Pi$ is not different from that over $\pi \rho$ at ii. 1 of the same text, where we clearly have $\varepsilon$, i.e., $\pi \rho \varepsilon\left(\sigma \beta v^{\prime} \tau \rho \rho \varsigma\right)$. $\left({ }^{6}\right)$ We may thus read $\Pi \varepsilon(\tau \rho o v)$ at $S B$ 15244.i.3 and ii.3. The fact that the name is not abbreviated at ii.7 (the papyrus has $\pi \varepsilon \tau \rho^{\mathrm{v}}$ or $\pi \varepsilon \tau \rho^{\circ}$ ) need not be a problem; cf. $\gamma \varepsilon \omega \rho^{\gamma}$ and $\gamma^{\varepsilon}$ at ii.3 and 6 (sim. P.Ross.Georg. V 71.5, 8, 10).

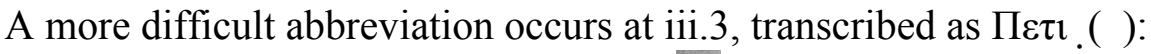

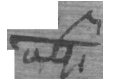

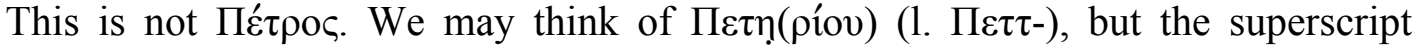
character is not unequivocally $\eta$ (contrast SPP XX 263r.i.3 and ii.18), and the short vertical stroke next to the foot of $\tau$ is confusing.

\section{SB XXIV 16141}

The name of the person recorded in 1.3 of this short list of payments of the seventh century was given as $\Gamma \varepsilon(\lambda \alpha ́ \sigma 10 \varsigma)(\gamma$ pap.), but the commentary acknowledges that "bei $\gamma \varepsilon$ wohl noch andere Möglichkeiten in Frage kommen könnten. Da die Abkürzung zumeist $\Gamma \varepsilon \omega$ lautet, scheint der viel üblichere Name Georgios nicht relevant zu sein". $\left({ }^{7}\right)$ This would not be decisive even if $\gamma \varepsilon \omega$ were a common abbreviation of this name

(6) Another example may be detected in $S P P \mathrm{X} 40.18$, for which Wessely produced a drawing,

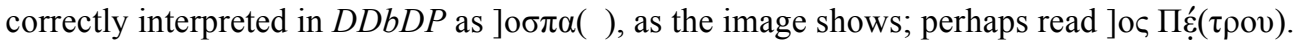

(7) H. Harrauer \& P.J. SiJPeSteijn (†), Papyri 2 (1997) 19. 
(which is not); as mentioned in the previous note, monosyllabic abbreviations suggest a very common name, such as $\Gamma \varepsilon \omega ́ \rho \gamma ı \varsigma$, or even $\Gamma \varepsilon \rho o ́ v \tau \imath \varsigma \varsigma,\left({ }^{8}\right)$ but certainly not

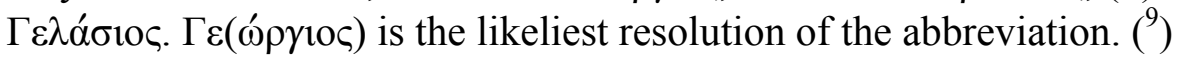

The numerical preponderance of this name over all others beginning $\Gamma \varepsilon$ - is probably behind the inclusion of $\Gamma \varepsilon($ ) under $\Gamma \varepsilon \omega ́ p \gamma$ io in the indexes to SPP III and VIII (pp. $225,235,289)$ and $X($ p. 172), although Wessely was not entirely certain: he read

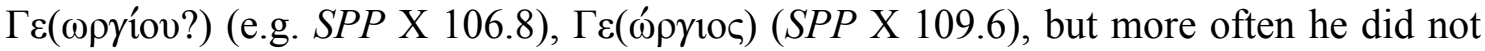
resolve the abbreviation. $\left.{ }^{10}\right)$ There are also instances where the resolution is guaranteed

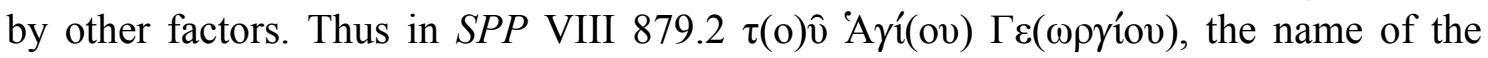
patron saint of the church, and here the associated district of Arsinoe, is not in doubt, since it is written out in full elsewhere. Then, the person called $\prod_{[}[\alpha \pi v o v]$ tio(v) $\Gamma \varepsilon \omega \rho \gamma\left(\right.$ íov) in $S P P$ XX 235r.5, recurs as $\Pi \alpha \pi v($ ov $) \theta$ (íov) $\Gamma \varepsilon\left(\omega \rho \gamma\right.$ íov) in 235v.i.31. ${ }^{11}$ )

\section{SB XXIV 16142}

The text written on the other side of the previous item is an account headed $\lambda$ ó ${ }_{0}(\varsigma)$ $\Theta \varepsilon \dot{\kappa} \lambda \eta(\varsigma)$. But this Thecla did not live in late Fayum. The image shows that the papyrus has $\bar{\lambda} \alpha \gamma_{t}$, i.e., $\lambda\left(\alpha v_{\rho} \rho \varsigma\right) \dot{\alpha} \gamma^{\prime}(\alpha \varsigma) \Theta \varepsilon \varepsilon^{\prime} \lambda \eta(\varsigma)$. This is a well-attested district of the Arsinoe, named after the church of St Thecla; cf. e.g. SPP X 6.6.

\section{SPP VIII 709}

The name of the payer's father in this receipt for diagraphon is now read as $\Sigma \varepsilon \rho \beta_{n}(\mathrm{ov})$, after $B L$ VIII 446; the reading is palaeographically acceptable (but there is no abbreviation: after the putative iota, a mere dot, the papyrus breaks off), but one cannot rule out $\gamma$, i.e., $\Sigma \varepsilon \rho \gamma$ y. [ov].

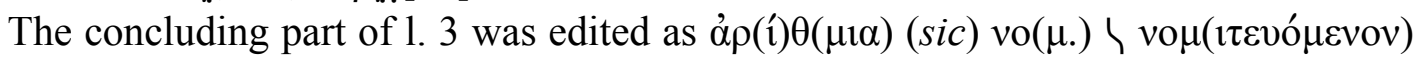
$\dagger \delta\left(l^{\prime}, \dot{\varepsilon}\right) \mu$ ov $\Sigma \varepsilon_{\ell}$. As we can see from the image, the subscription and name are not

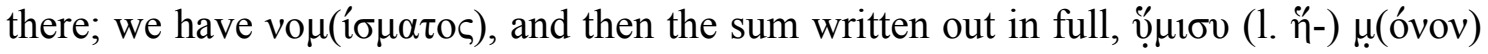
(the top of $\mu$ is minimal, but the two obliques marking the abbreviation are characteristic). There is something in between that looks like $\varepsilon$; as N. Vanthieghem suggests, could it be that the scribe wrote $\varepsilon \dddot{\mu} \mu \imath v$ ?

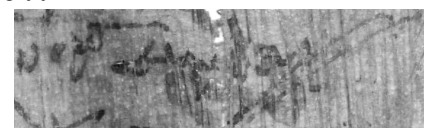

\section{SPP VIII 756}

The subscription to this receipt for diagraphon was read as $M \eta(v \hat{\alpha} \varsigma) \mid \delta \eta \mu^{\omega} \sigma \operatorname{í}^{\left({ }^{(?)}\right.}$

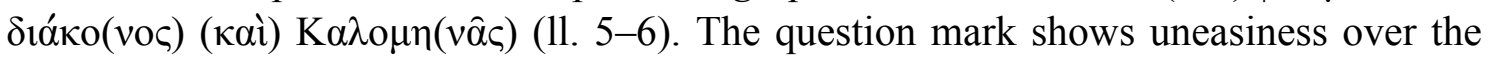
unexpected word. Here is a clipping of the image of the relevant passage:

(8) Cf. M. Weissl, AnPap 5 (1993) 58; P. SArischoul, Tyche 12 (1997) 185; sim. L. Berkes \& B. HAUG, BASP 53 (2016) 207, who do not resolve $\Gamma \varepsilon($ ) in several passages of P.CtYBR inv. 461 on the grounds that the name $\Gamma \varepsilon \omega \rho \rho \gamma ı \varsigma$ is written more fully elsewhere in the text, but such inconsistencies are common.

(9) In 1. 8, П $\alpha \hat{v}(\lambda \circ \varsigma)$ is a slip for $\Pi \alpha \hat{v} \lambda(o \varsigma)$.

(10) In a later publication, $S P P X X 281.9$, Wessely read $\Gamma \varepsilon($ ) and did not index the name.

(11) See ZPE 186 (2013) 271. 


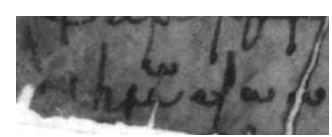

The superscript $\omega$ indicates an abbreviation, and what follows should belong to a different word. There is also writing before $\eta$ which cannot be part of $\delta$ but would be

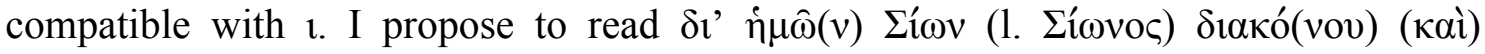
$\operatorname{K} \alpha \lambda \mathrm{o} \mu \eta(v \hat{\alpha})$; Menas was represented by two other persons.

\section{SPP VIII 887}

This is a short fiscal register of the eighth century written on parchment, now in poor condition. The beginnings of 11. 3-4 were presented as follows:

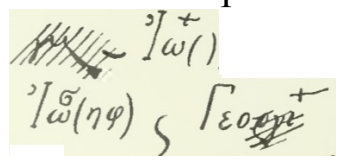

The unread name in 1.3 is ' $H \lambda i(\alpha)$, and $\Gamma \varepsilon 0 \rho y !(~)$ in 1.4 conceals two names; the

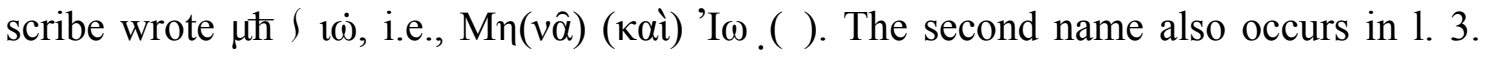
What is written over omega does not seem compatible with alpha but can hardly be sigma, in view of ' $I \omega \sigma\left(\eta^{\prime} \varphi\right)$ in 1. 4; Wessely's crosses are fair reproductions of what is

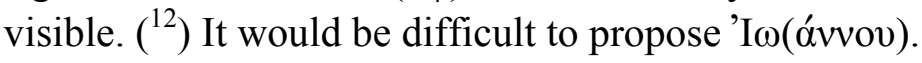

\section{SPP VIII 1309}

This Heracleopolite document (cf. BL XI 262) contains a list of witnesses' subscriptions and refers to $358 \kappa\left(o^{\prime} \lambda \lambda \alpha\right) \theta(\alpha)\left(\kappa^{\theta}\right.$; not resolved in ed. pr.), certainly of wine (as N. Vanthieghem points out, the Coptic subscription mentions a пбемн, a vinedresser). It has been claimed, "haben wir bei dem Zeugen in Z. 2 (vgl. Z. 1, 3 und 4) sicherlich auch Name und Beruf und nicht Name und Vatersname anzunehmen", $\left({ }^{13}\right)$ with $\Gamma \varepsilon \omega \rho \gamma($ íov) turned to $\gamma \varepsilon \omega \rho \gamma($ óc) as a result. The change is unnecessary; a father's

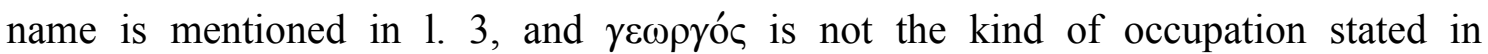
subscriptions. $\left({ }^{14}\right)$

The concluding line (7) ends 'A $\theta \alpha v \alpha \sigma \iota^{\gamma} \gamma t y^{\theta}$ in the edition; this should be read as

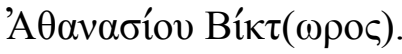

\section{SPP X 41, etc.}

The papyrus consists of two contiguous fragments, but this was not recognized in $e d$. $p r$., where they were published in reverse order relative to the original. $\left({ }^{15}\right)$ A new text with notes is given below.

(12) F. Morelli (to whom the reading ' $H \lambda i^{\prime}(\alpha)$ in 1.3 is due) describes it as something 'che sta tra un $\theta$ aperto in alto a destra e uno $\varepsilon$ chiuso in basso a destra'.

(13) J. DietharT, Tyche 10 (1995) $237=B L$ X 267. The correction to a reading in 1.3 proposed in the same place had been anticipated by the same author fifteen years earlier; see $B L$ VIII 453.

(14) In SPP VIII 879.1 'A $\pi \alpha \Phi 1 \beta \Gamma \varepsilon \omega \rho \gamma$ (íov) pays rent for a property of the church of St Georgios, known to be located in the city of Arsinoe. Contrary to the suggestion in BL VIII 448, it is not likely that we have to resolve $\gamma \varepsilon \omega \rho \gamma(\mathrm{ov})$.

(15) This was first pointed out by F. MORELLI, CPR XXII 40.4 n. (= BL XII 271). 


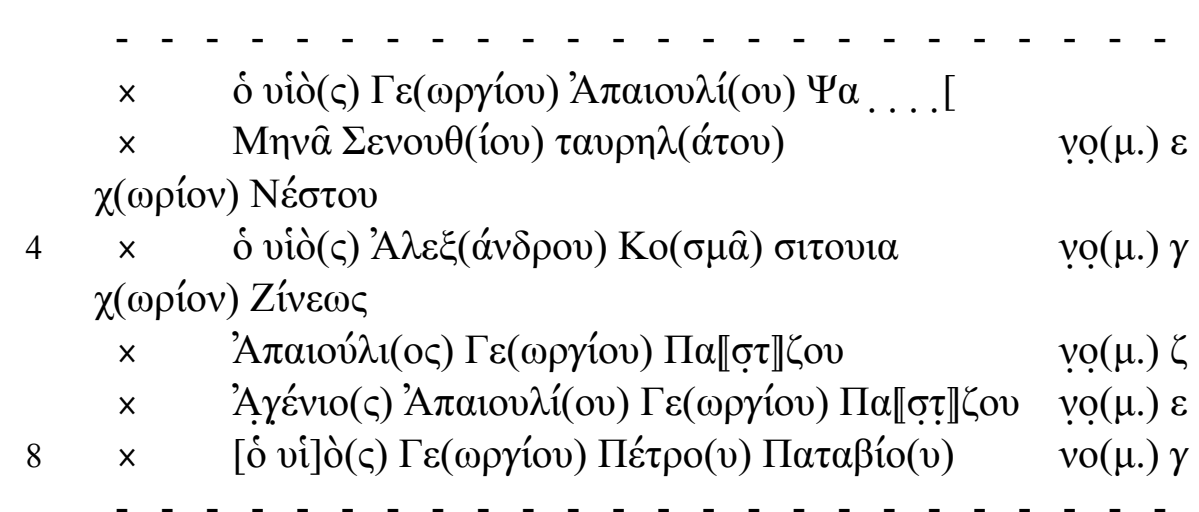

$1 \mathrm{x}: \chi(")=\chi($ (๓íov $) e d . p r$. The same applies to $11.2,4,6-8$. This is a checkmark, not an abbreviation; for a similar problem in SPP X 187.4, see Tyche 25 (2010) 208. The entries in the topographic repertories that have resulted from this misunderstanding should be deleted.

ó vió(c). Cf. 4,8 . It is generally held that such 'sons' are under age; see $C P R$ XXII $40.4 \mathrm{n}$. Contrast the person listed in 1. 7, who is probably the son of the one recorded in 1. 6; this would also explain the sequence of four names instead of three in 1. 7.

$\Gamma \varepsilon\left(\omega \rho \gamma^{\prime}\right.$ ov $): \gamma\left(\alpha \mu \varepsilon \tau \tilde{n}^{\prime}\right) e d . p r$. Cf. also 6-8. See the discussion below.

$\Psi \alpha \ldots$... [: T $\alpha \mu / / / /$ ed. pr. The reading of $\Psi$ was suggested by F. Morelli. A. Delattre compares P.Horak 64.12 'A $\pi \alpha 10 \hat{\lambda}(10 \varsigma) \Psi \alpha \mu \varepsilon \ldots$.. ( ).

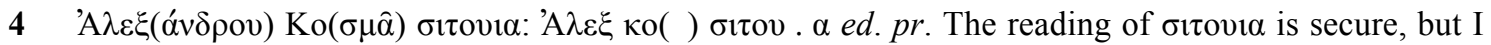
do not know what it means. On $\operatorname{Ko}(\sigma \mu \hat{\alpha})$ see further below.

$6 \quad \Pi \alpha \llbracket \sigma \tau \rrbracket \zeta o v: ~ \Pi \alpha \rho o v$ ed. $p r$. Cf. 7. $\sigma \tau$ i is overwritten by $\zeta$. Presumably a name.

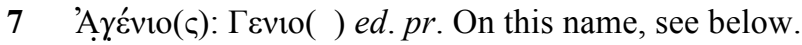

$\Pi \alpha \llbracket \tau \rrbracket \zeta o v:$ Патоv ed. pr.; Пароv BL VIII 454.

8 [ó ví] $(c):] \mathrm{o}($ ) $e d . p r$.

Three of the revised readings call for additional comment. The context rules out that $\gamma(\alpha \mu \varepsilon \tau \eta$ ) occurs anywhere in the text; a name is needed, which must be $\Gamma \varepsilon(\omega \rho \gamma$ íov) (see above, no. 7). $\left({ }^{16}\right)$ The type of the abbreviation stroke used is not conclusive, being compatible with either $\alpha$ or $\varepsilon$ (see above, no. 2). Wessely may have been influenced by SPP X 30, now P.Horak 64, where a similar abbreviation stands for $\gamma(\alpha \mu \varepsilon \tau$ ) $)(11.8,15-$ 17). $\left({ }^{17}\right)$ The same word is abbreviated somewhat differently in P.Horak 65.11, 13, 15 , and $66.2-7$; P.Horak $66.6 \gamma \alpha(\mu \varepsilon \tau \grave{)}) \Gamma \varepsilon(\omega \rho \gamma$ íov) offers a clear illustration of the two shortenings.

The abbreviation $k^{0}$ for $\operatorname{Ko}(\sigma \mu \hat{\alpha} \varsigma)(1.4)$ is known from other fiscal registers of this period, but this gave difficulty in the early years of papyrology. Thus in SPP X 80.11, $[\Sigma] \varepsilon v o v \theta(10 \varsigma) \mathrm{K}(\mathrm{)})$, there is an unnoticed $\operatorname{Ko}(\sigma \mu \hat{\alpha})$ : o is the loop at the top of the abbreviation stroke. Another passage where the abbreviation was not understood is $S P P$ $\mathrm{X} 106.5$, where we have $\operatorname{Ko}(\sigma \mu \hat{\alpha})$; cf. also below, nos. 15 and 23. The o is sometimes

(16) I alluded to this problem in ZPE 136 (2001) 120 n. 5. My point of departure was the text now referenced as $S B$ XXIV 16210, where I proposed $\gamma \varepsilon(\omega \rho \gamma o ̀ \varsigma) ~ \Pi i ́ \omega$ (ii 5) as an alternative to $\Gamma \varepsilon(\omega ́ \rho \gamma 10 \varsigma) \Pi i ́ \omega$ and to $e d$. $p r$.'s $\Gamma \varepsilon(\rho o v \tau i ́ o v)$ Пí $\omega$, which would remove the problematic juxtaposition of four names. The proposal did not carry as much certainty as the text printed in $S B$ implies, and I am sceptical about this choice. A name now appears to me more likely than $\gamma \varepsilon(\omega \rho \gamma o ́ c)$.

(17) There is no context in the writing exercise $C P R$ XIX $29.1,15,18,19,54-64$, where $\gamma \alpha(\mu \varepsilon \tau)$ is the suggested resolution, but we could also think of $\Gamma \varepsilon(\omega \rho \gamma \gamma(0 \varsigma)$, even if this name is written as $\Gamma \varepsilon \omega \rho \gamma 1$ in 1 . 26. Another passage where $\gamma \alpha(\mu \varepsilon \tau \eta \dot{)})$ was later read as $\Gamma \varepsilon(\omega ́ \rho \gamma 10 \varsigma)$ is $S P P$ XX 277.7 (see BL VIII 478; but this is a conjecture, not a correction made 'am Original'). Cf. also below, no. 20. 
hardly visible; one such case is $\operatorname{SPP} \mathrm{XX} 206.6$, where after $₹$ the scribe added $\mathrm{c}^{\bar{\mu}}$, perhaps for clarity; the same scribe wrote $\kappa^{0}$ for $\operatorname{Ko}(\sigma \mu \hat{\alpha} \varsigma)$ in $1.10(\mathrm{~K}() e d$. pr.), but $\operatorname{Ko} \sigma \mu(\hat{\alpha})$ in 1. 3. This is a standard shortening of this name; $\left({ }^{18}\right)$ for the equivalence, $\mathrm{cf}$. the person called K. [o] $\sigma \mu \hat{\alpha} \Sigma \alpha \varepsilon 1 \alpha$ and $\mathrm{Ko}(\sigma \mu \hat{\alpha}) \Sigma \alpha \varepsilon 1 \alpha$ in SPP XX 235r.7 and v.ii.17 respectively; $\left({ }^{19}\right)$ cf. also CPR IV 110.1 and 19, космд (read by A. Delattre; кєсмд ed. $p r$.) and $\operatorname{Ko}(\sigma \mu \hat{\alpha})$. The other common name that began Ko-, viz. Ko $\lambda \lambda$ ov̂ $\theta$ oc, is longer and contains more consonants, so that in its abbreviated forms at least one of the other consonants was written after $\mathrm{K}$ or Ko.

The new reading 'A $\gamma \varepsilon^{\prime} v 10(\varsigma)$ in 1.4 removes one of the few putative examples of the

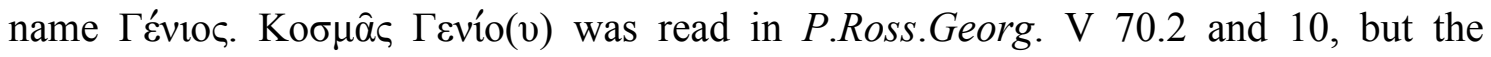
published photograph (Aegyptus 13 [1933] 86) shows that this has to be corrected to

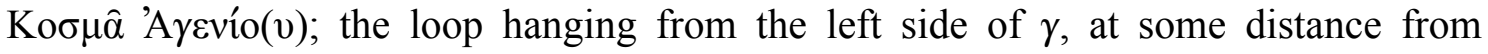

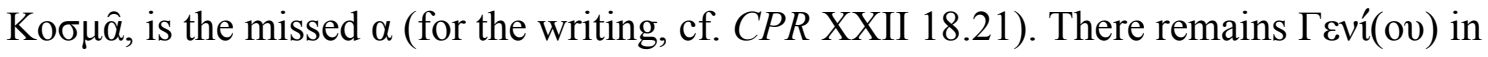
$C P R$ XXII 49.5, but the surface before $\gamma$ is damaged and no reading can be confirmed.

\section{4. $S P P \times 60$}

There are a several curious names and other peculiar readings in this text. Some of them will be discussed here.

Wessely transcribed $\delta(i \grave{\alpha}) \operatorname{Av} \rho^{-(}$) $\Phi 1 \beta$ at ii.3; the abbreviated name was resolved as

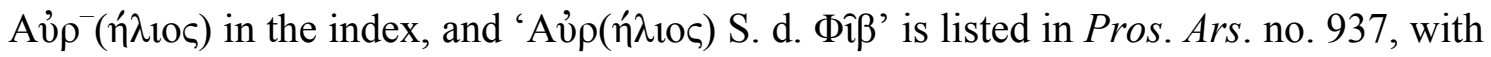
the note, ' $\Phi i ̂$ ist hier offensichtlich Patronymikon' (p. 352 n. 164). It would be odd to find someone whose first name was Aúpí $\lambda$ ioc in a text of this date, but at first sight the reading of $\alpha v \rho$ looks good; only the abbreviation stroke, a superscript horizontal, does not suit a shortening at $\eta$. I believe the scribe intended to write 'A $\beta \rho(\alpha \alpha \mu$ íov); he wrote the three letters without lifting his pen, and the u-shaped beta suffered as a result of the speed. 'A $\beta \rho \alpha(\alpha \mu$ íov) at i.13, written more slowly, looks different.

\section{ii. 3}

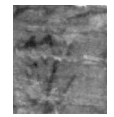

ii. 10

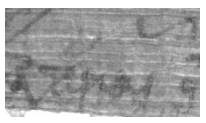

Another onomastic oddity turns up at ii.10, $\delta(1 \grave{\alpha}) \Pi \mu \alpha \iota^{v}$; the name was indexed as

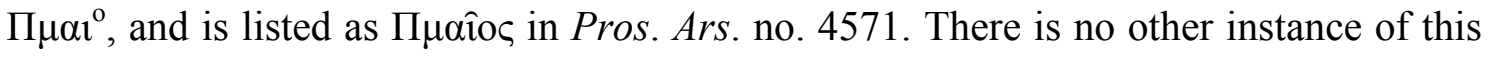
name; Pmai (TM Nam 27433) is known exclusively from the Memnonia and environs. Here the reading was obscured by an abbreviation, but not of one of the name itself. What was read as $\Pi$ does not have a fully formed second loop, while the expected crossbar covers only the first loop, and without touching it. This short horizontal is part of an abbreviation: the scribe usually abbreviates $\delta 1 \alpha$ by adding an oblique stroke after $\delta$, but occasionally also adds a short horizontal level with the top of $\delta$, as if he intended to write $\delta(1 \grave{\alpha}) \tau($ ) (here ruled out by the context). Wessely duly recorded it at i.9, 13, and ii.6-7, but failed to record it here and at i.8. Once the horizontal is separated from what lies underneath, we remain with $\alpha$ : the papyrus has 'A $\mu \alpha$ íov.

A name that occurs twice in the text but not in the transcription is $N \alpha \alpha \rho(\alpha v)$ : at 1.10 Wessely only drew a facsimile of what he could make out, while at ii.5 he read $\Sigma \alpha \mu \beta(\hat{\alpha})$. In both cases the scribe wrote $v \alpha \alpha \bar{\rho}$ (at i.10, the second $\alpha$ is vestigial).

(18) Wessely recognized this later, and printed $\operatorname{Ko}(\sigma \mu \hat{\alpha})$ in $\operatorname{SPP} \mathrm{XX} 235.16,17,19,264.10,11,13$, 281.25.

(19) See ZPE 186 (2013) 271. 


\section{SPP X 74}

$\Sigma \alpha \mu \beta \alpha \theta$ (íov) (or $\Sigma \alpha \mu \beta \alpha \theta$ (í⿴voc); cf. BL VIII 454) makes an unexpected appearance at r.ii.7 of this text in view of its late date. Inspection of the image results in something banal: $\Sigma \alpha \mu \beta \hat{\alpha} \delta 1$ ( $\alpha$ Kóvov).

Two lines above (r.ii.5), Wessely transcribed ' $\mathrm{E}[\quad] \kappa^{\mathrm{o}}$. I propose to read $\varepsilon$. v . ío(v) $\operatorname{Ko}(\sigma \mu \hat{\alpha}) \Sigma \alpha \varepsilon 1 \alpha$; what remains of the first name would admit $\varepsilon v o v \theta$ ío(v), but there is no

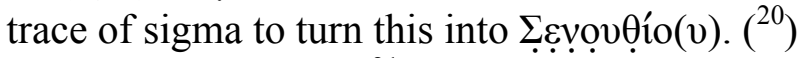

I close this note $\left({ }^{21}\right)$ with another point of paleographic interest that has onomastic implications; I juxtapose Wessely's readings and image clippings:

r.ii.2 $\delta(เ \grave{\alpha}) \Pi \alpha v \lambda^{o v}$
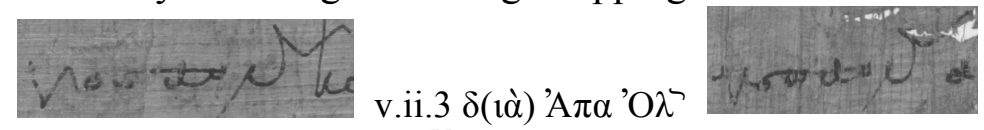

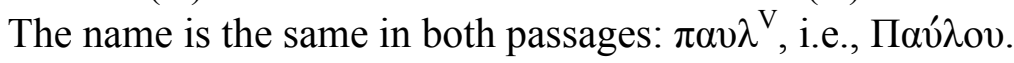

\section{SPP X 79, etc.}

According to Pros. Ars., this late tax register appears to attest three persons called $\Phi \lambda$ áovïos (nos. 5413-15). $\Phi \lambda$ áovïoc is not found as a personal name after the early Principate, and its use as a gentilicium in this period is extremely limited. The first and third of them occur at i 2 and 4, after BL VIII 455: 'I $\omega$ [ávvnc] $\Phi \lambda \alpha$ [ovíov] and 'A $\mu \alpha i ̂(\varsigma)$

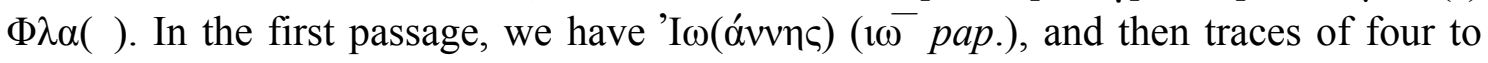
five letters before the lambda; there is no phi. In the second passage, there is no abbreviation, and the text continues $\pi \circ \mu(\eta \dot{\eta} v)$; it would be preferable to read $\Phi \lambda \alpha$, and relate it with $\Phi \lambda \alpha \varsigma$, a name attested in P.Prag. II 136.9 (Ars.; VII). Another instance hides under $\Phi \lambda \alpha($ ) in SPP X 146.2 (Pros. Ars. no. 5409); here too read $\Phi \lambda \alpha$, since there is no abbreviation. $\left(^{22}\right)$

The second of the three putative Flavii in SPP X 79 was thought to occur in 1.3 of the text on the back, which was omitted from the published transcription. The papyrus

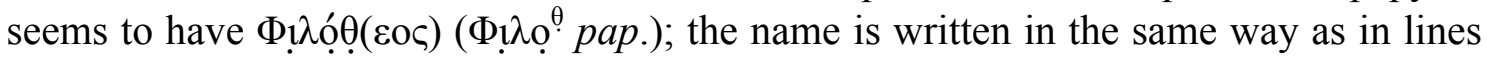
'7' and '9' of the same column. Another alleged $\Phi \lambda$ áovïos (Pros. Ars. no. 5412) who is

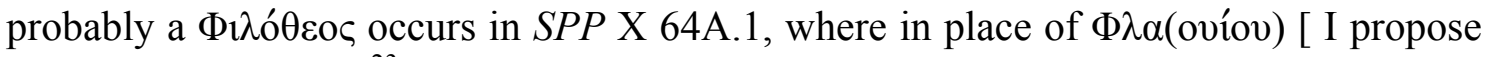
to read $\Phi ! \lambda \mathrm{o}\left[\theta \dot{\varepsilon}(\mathrm{ov}):\left({ }^{23}\right)\right.$

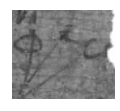

(20) Much has gone astray in the edition of the second column of the 'recto' of this text. The parts of 11. 2-3 that follow the toponyms correspond to 11. 1-2 (the entries follow the scheme: $\chi \omega \rho$ (íov) name $+\delta(1 \grave{\alpha})$ personal name + amounts of money). What is given as 1.3 does not exist, so that the lines have to be renumbered; 1. 3 is the current 1. 4, starting $\chi[\omega \rho$ (íov)] ( $\chi \omega \rho($ íov $) e d . p r$.) $\Sigma \tau \rho \alpha ́ \tau \omega v o \varsigma$. In 1. 12, after

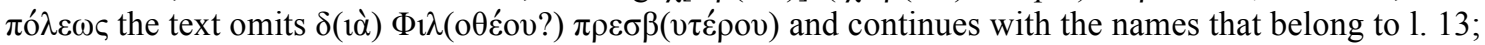
this affects the remaining part of the column, which has to be adjusted accordingly; but the numbers at the end of the lines are correctly positioned.

(21) Numerous other points in the rest of the text require discussion; a study by L. Berkes is in preparation.

(22) Checked on the original by F. Morelli, whom I thank. I have not been able to see a reproduction of SPP X 278.8 (Pros. Ars. nos. 5411), where $\Phi \lambda \alpha($ ) appears to be a personal name.

(23) The name of the person in Pros. Ars. no. 5410 has been re-read as $\Phi$. ( ) in SPP III ${ }^{2} .5506 .2$; the papyrus has $\varphi \imath^{\lambda}$, i.e., $\Phi \imath \lambda(o \theta \varepsilon ́ o v)$. 
The third letter is $\lambda$, not $\alpha$; the letter before it, raised, does not immediately suggest 1 , but there is no other option. When writing $\varphi \imath \lambda$, scribes generally made the iota small. This iota could have a curved form (cf. e.g. CPR II 203.4 or SPP XX 264v.10), and here this curve is very pronounced and written high in the line.

Similar problems come up in SPP X 179; I reproduce two passages as these appear in the edition, accompanied by the relevant clippings:

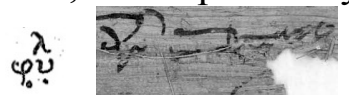

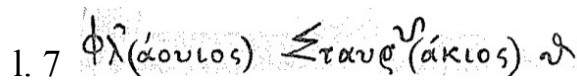

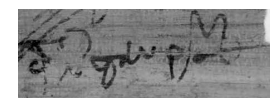

In both passages we have $\varphi \mathrm{r}$ with $\lambda$ superscript, though the shape of $\lambda$ in 1.7 is rather peculiar, $\left({ }^{24}\right)$ and it is clear why $\underline{v}$ was read in 1.5 ; still, it can hardly be $\varphi v ́ \lambda(\alpha \xi)$, given that $\Phi$ or $\beta(\alpha \mu \mu \omega v) \delta 1 \alpha(\kappa o v o \varsigma)$ is written before. $\Phi ı \lambda($ ) is a common abbreviation, and has often remained unresolved; of the texts discussed in this article, cf. SPP XX $281.5,10,23,25$ (no. 23). $\Phi$ i $\lambda$ - could be the beginning of more than one name, with $\Phi 1 \lambda$ (o $\theta \dot{\varepsilon}$ ov) being the likeliest option; $\Phi 1 \lambda(\mathrm{o} \xi \dot{\varepsilon} v o v)$ may also be considered, but the name is less frequent than Philotheos in Arsinoite texts of this period.

In 1. 5, what follows $\varphi \imath \lambda$ did not find its way into the edition: $\Gamma \varepsilon(\omega \rho \gamma$ íov) 'A $\pi \alpha \omega \lambda$. As for 1.7 , the name is certainly $\Sigma \tau \alpha v \rho \alpha ́$ kioc, but I am not sure whether the superscript letter is $v$, indicating the genitive, or, less likely, $\kappa$. This is followed by a cross.

To return to $S P P$ X 79, a few other textual problems could be addressed here. After $B L$ VIII 455, the name of the village at 1.8 is followed by traces . $\rho 1 \Sigma \omega v$. .[; what is visible before the edge of the break is $1 \bar{\omega}$, which suggests reading - $\rho \iota \varsigma$ ' $I \omega(\alpha$ 'vvov); final $v$ does not have this form in mid line. Onomastic curiosities occur at ii.8, N $\varepsilon \varphi \varepsilon(\rho \hat{\alpha} \varsigma)$ $\mathrm{N} \alpha \beta \mathrm{l}$ ( ) 'Pov́ $\pi(\mathrm{ov})$ (with $B L$ VIII 455); the last two names are found only in this text, but on closer inspection $\mathrm{N} \alpha \beta \mathrm{l}$ ( ) turns out to be a 'ghost': read $\mathrm{N} \alpha \alpha \rho(\alpha v)(v \alpha \alpha \rho \overline{-}$ pap.), frequent in this area. On the other hand, the reading of the name at the end of ii.9

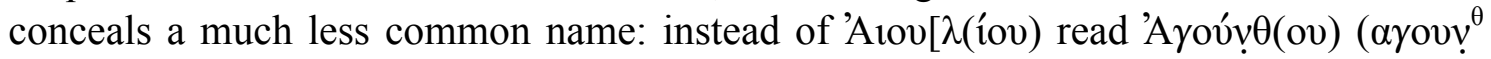
pap.).

\section{SPP X 85}

Wessely read $\Sigma \alpha \mu^{\beta(\alpha)} \operatorname{Ko} \lambda(\lambda \circ v 0$ ov?) in 1.4 of this fragmentary tax register of the eighth century. The second of the two names does not need a question mark (there are no viable alternatives at this time), but $\Sigma \alpha \mu \beta(\hat{\alpha})$ is wrong; the papyrus has c $\alpha \mu^{\mathrm{V}}$ :

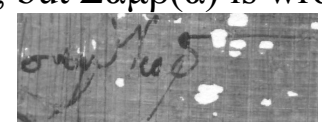

I propose to read $\Sigma \alpha \mu o v\left(\eta^{\prime} \lambda\right)$. The same person, with both names abbreviated as in 1 . 4 , occurs two lines below (not reported in ed. $p r$.). Further examples come from SPP XX 242.63 and 64, where the name was transcribed and indexed as $\Sigma \alpha \mu^{\mathrm{ov}}$. It is given as

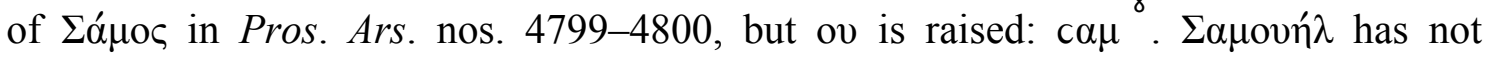
occurred in very many documents of this period, but there is no other suitable candidate.

\section{SPP X 117v}

(24) I would also be inclined to read $\Phi$ 1 ( ) rather than $\Phi v \lambda($ ) in P.CtYBR inv. 461.43 (see BASP 53 [2016] 214, 222). $\Phi v \lambda($ ) in SPP VIII 870.3 is suspicious, but I have not seen an image of the papyrus. 
More is visible on the papyrus in lines 1-4 than what was reported in the edition, perhaps the result of conservation in recent years. A new text may be presented as follows:

\author{
$\mathrm{Xa \eta ̀ \lambda} \ldots[] \ldots[$

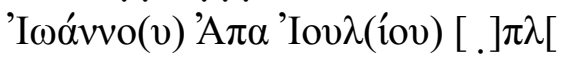

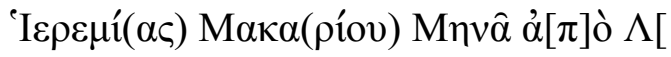

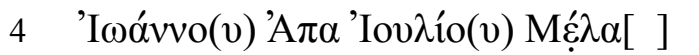

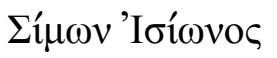 \\ $\operatorname{vo}(\mu.) \alpha$

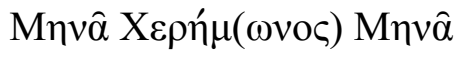 \\ $\operatorname{vo}(\mu) \quad v o.(\mu$. \\ $\underline{v o(\mu .)} \varsigma \gamma^{\prime} \eta^{\prime} \quad v o(\mu.) \alpha \gamma^{\prime} \kappa \delta^{\prime} \mu \eta^{\prime}$

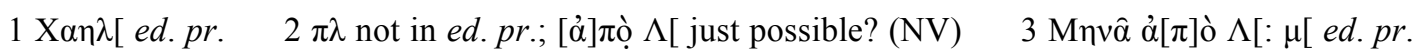 \\ 4 Mẹ́ $\lambda \alpha[$ ]: $\mu[e d . p r$.; perhaps Mẹ́ $\lambda \alpha$ was intended as a genitive (cf. e.g. SPP VIII 748.2) 61. \\ Хаıри́ $\mu \omega v o \varsigma$ (cf. $B L$ VIII 456)
}

Some of the abbreviations are interesting. Apart from $1 \omega \alpha v v$ in lines 2 and 4, typical of Arsinoite fiscal registers of the later eighth century, there are two false reduplications of the last consonant before the abbreviation: $\varepsilon \varepsilon \rho \varepsilon \mu \bar{\mu}$ in 1.3 , and $\chi \varepsilon \rho \eta \mu \mu$ in 1.6 .

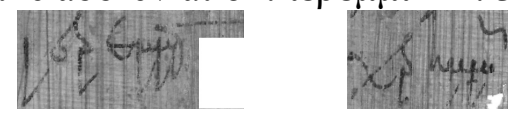

$\chi \varepsilon \rho \eta \mu \mu$ is curious: the superscript character normally represents $v$; its use may be indicative of confusion, not uncommon in this period, unless the scribe intended to write ov instead of $\omega$. As for $1 \varepsilon \rho \varepsilon \mu \bar{\mu}$, the abbreviation stroke suggests $\alpha$, hence the nominative. The use of cases in these lists is generally erratic, with nominatives (here also at 5$)$ found alongside genitives $(3,4,6)$, but genitives generally predominate.

\title{
19. SPP X 216
}

This is a fiscal register from Heracleopolis of the eighth century. The text has received some critical attention, but a few problems remain. Progress is possible in 1. 6, B $\alpha \rho \theta 0 \lambda($ o $\mu \alpha \hat{\imath} о \varsigma) \delta 1 \alpha(\kappa o v o \varsigma) \Sigma \tau \alpha v \rho(\alpha \kappa i ́ o v)$ : the image shows that the last name should be read as $\operatorname{N} \alpha \alpha \rho(\alpha v)$. We are on less firm ground with Tavv( ) in 1. 7; the first letter is a

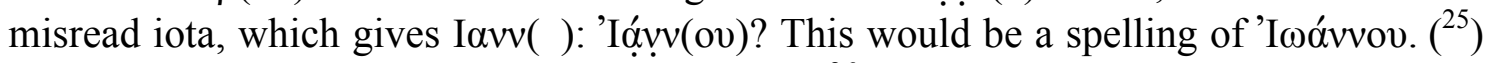

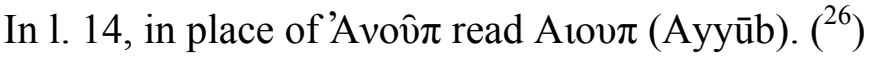

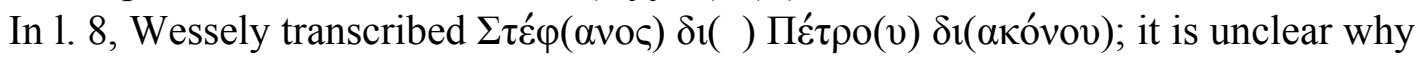
he did not expand $\delta$ iá(коvоc), as elsewhere in the text (not indexed). $\left({ }^{27}\right.$ )

\section{SPP XX 206}

(25) See H.C. Youtie, ZPE 28 (1978) 268 (n. 1. 3). YoutiE refers to 'Ióvov in O.Petr. 461.1 as an

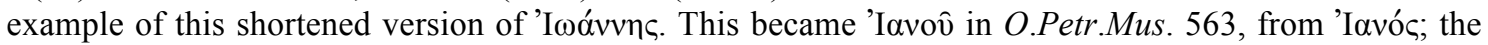
same form occurs in $S B$ XXIV 16208.8. (To judge from the image at $<$ http://data.onb.ac.at/rec/RZ00008156>, 'Ióvv(o)v in the Arsinoite CPR II 203.5 is wrong; F. Morelli tentatively suggests $\alpha \mu \omega^{v}$. Before it, for $\Delta \alpha v \delta$ read $\Delta \alpha v i \delta$.)

(26) See M. Legendre, 'Répertoire des anthroponymes arabes attestés dans les documents coptes', in Coptica Argentoratensia (2014) 408; another example in SB Kopt. II 929.3.

(27) The version that appeared in $D D b D P$ in the 1990 s interpreted it as $\delta 1(\alpha)$, but the abbreviation is the

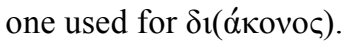


The text was assigned to the seventh century, but probably belongs to the eighth. It lists men from the Heracleopolite $(\times 2)$ and Oxyrhynchite $(\times 6)$ pagarchies, and others

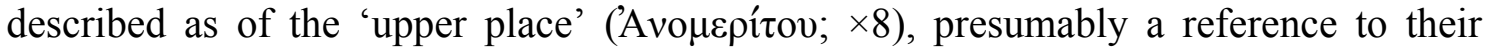
origin from Upper Egypt (see P.Gascou 32.22 n.); of two others the description is unclear. Perhaps they were all resident or even fugitives in Arsinoe, and this register served some fiscal purpose. Every entry ends with the number ' 1 ' (ed.'s $\beta$ in 1.3 could also be an odd-looking $\alpha$ ). Dots are visible before the numbers in 11. 2-4, which will be the abbreviation for vó $\mu 1 \sigma \mu \alpha$, if intentional. In 1.1 , the number is preceded by $\mu$, an obscure abbreviation. It recurs in SPP XX 249, written over the third column on the back; '1. $\mu \varepsilon \gamma \alpha$ ' $\lambda \alpha$ ', wrote Wessely, but this cannot be right. In that text too entries end in $\alpha$ or $\beta$ (see below, n. 28 ), with a dot $=$ vó $(\mu 1 \sigma \mu \alpha)$ written before them.

We move on to some names. The various renderings of Koб $\mu \hat{\alpha} \varsigma$ are described above, under no. 13. The first drastically abbreviated name occurs in 1 . 4, where the edition has $\gamma(\alpha \mu \varepsilon \tau \eta)$ Kov $\rho \eta \alpha$. The shape of the abbreviation stroke over $\gamma$ is

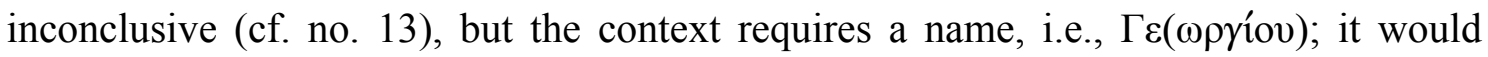
have been more difficult to decide if another name came after Kov

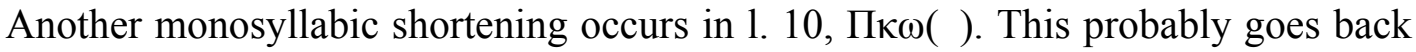

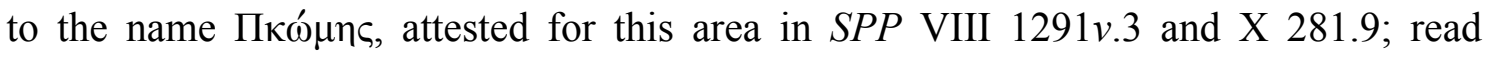

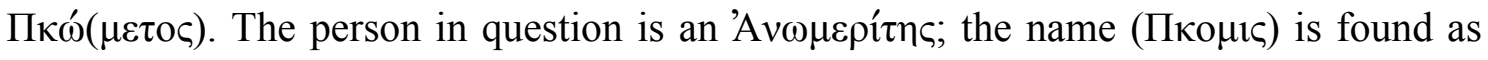
far south as Aphrodito.

A much more common name but in less common spelling occurs in 11.5 and 13, $\Pi \alpha \omega \mu($ ). We should read $\Pi \alpha \omega \mu(\hat{\alpha})$; cf. SPP III 343.7 (after BL IX 334) П $\alpha \omega \mu \hat{\alpha} \varsigma$, or P.Rain.Unterr. 80.27 П $\alpha \omega \mu \alpha$. The same abbreviation, resolved as $\Pi \alpha \omega \mu \alpha \hat{\alpha}(\varsigma)$, occurs in the Heracleopolite $C P R$ XXII 41.3.

The name of the father of the person in 1.12 was read as $\Sigma \varepsilon \rho(n v o v) \bar{\mu}($ ), but what was taken as an abbreviation stroke attached to $\rho$ is part of the letter. We have $\Sigma \varepsilon \rho \mu($ ); it would be surprising if the name were $\Sigma \varepsilon \rho \mu \eta \hat{~} \varsigma$, found only in two third-century Arsinoite documents (P.Giss.Univ. VI 49v.iii.1; P.Mich. XI 620.50). The origin of this

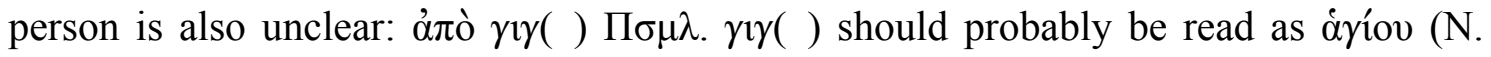
Vanthieghem), but what follows is more difficult.

The names should be resolved in the genitive (cf. 1l. 1, 6, 9-11, etc.); hence read

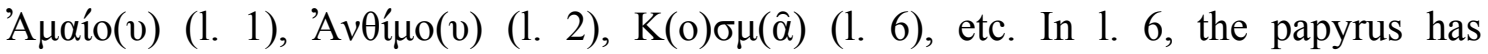

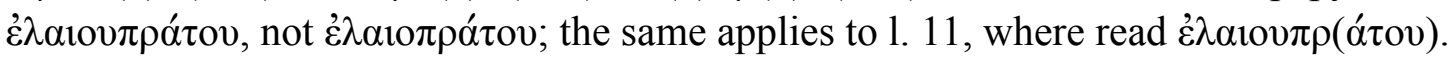

\section{SPP XX 242}

This is another tax register of the eighth century, but from the Fayum. The text occupies both sides of the papyrus, with the 'verso' being very crowded. The edition shows two columns of writing arranged unevenly against each other; the image offers more detail. Many lines in the right-hand column are written by a formal cursive hand, similar to that responsible for the text on the 'recto'. Other lines, including what look like interlinear additions and the entire left-hand column are in a more informal script, not necessarily the work of a different scribe. The format and high number of repetitions suggest that much if not everything written on the 'verso' is writing practice. 
Numerous readings of the first edition have already been revised, but there is more to comment on. Thus in 1. 43 on the 'verso', in a part written by the more formal hand,

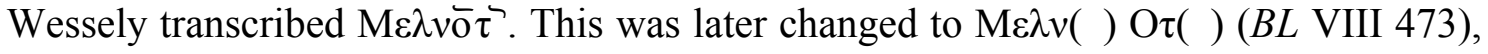
which however is not an improvement. The scribe wrote an abbreviation sign high in the line to the right of $\lambda$, then penned vo $\tau$ immediately after $\lambda$, and finally added another abbreviation sign of the same shape as the fist. There is something similar in 1. 10, where Wessely read $\mathrm{M} \varepsilon \lambda($ ):

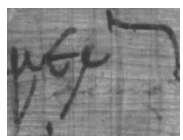

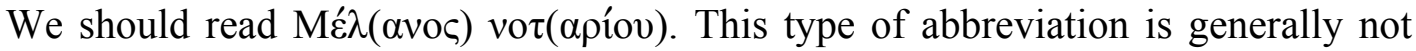
common for syllables ending $-\alpha$, but this scribe uses it for $\Theta \omega \mu \hat{\alpha}$ in 1. 46, for example.

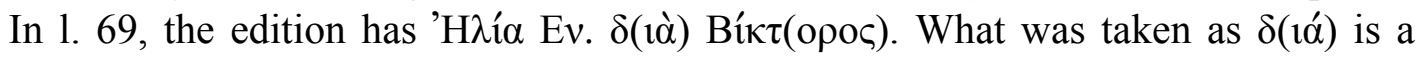

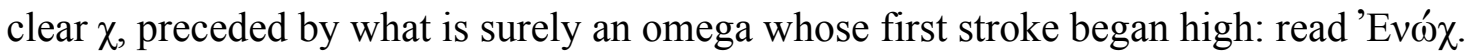

Some names are spelled phonetically. One of them is $\Delta \mu o_{0} \theta(\varepsilon \circ \varsigma)$, for Tuнó $\theta \varepsilon \circ \varsigma$, which occurs twice in 1.65 (cf. $B L$ VIII 474). Another is $\Delta \varepsilon 0 \varphi$ í $\lambda$ (ov), previously read as $\Theta \varepsilon o \varphi$ í $\lambda$ (ov) in 11. 28 (with $B L$ VIII 473; $\delta \varepsilon \delta 1 \varepsilon($ ) ed. pr.), 40, 41, 51, 52, 59, 60, 71, and 72; cf. $\Theta \varepsilon \circ \delta->\Delta \varepsilon$ o $\delta$-, discussed below, no. 23.

Of the problems that remain, one is an abbreviation in 1.7 on the 'recto': $\delta 1()$. We should resolve $\delta 1(\alpha$ Kóvov); -1( $\alpha$ )- is not abbreviated differently in $\delta 1(\alpha$ Kóvov) in 1. 3.

\section{SPP XX 249}

This is a late eighth-century register ('VII/VIII' ed. $p r$.) written in a minute hand. A number of new readings have been proposed by J. Diethart, Tyche 4 (1992) 236 (= BL IX 350). Certain points call for further comment.

According to Diethart, in 1.1 of the text on the front, "Das Patronymikon des

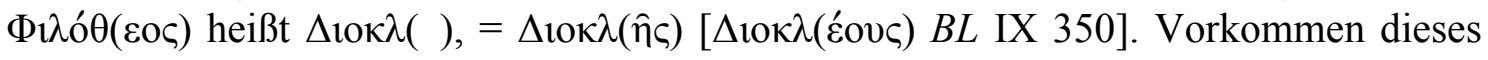
bis in römische Zeit häufig belegten Namens überrascht in diesem späten Text". Perhaps there is no such surprise. The papyrus has $\delta$ tok followed by a letter high in the line, I prefer to read as $\delta$. We may compare $\pi \delta 101 \kappa^{\delta}$ in in 1.3 of the text on the back; this was another new reading proposed by Diethart, who noted: "Vielleicht haben wir es mit

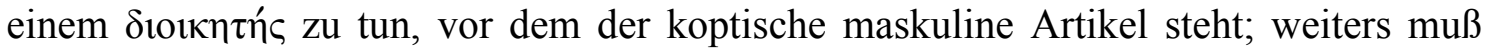
man einen Schreibfehler $\delta$ statt $\tau$ annehmen." I wonder whether Philotheos is a

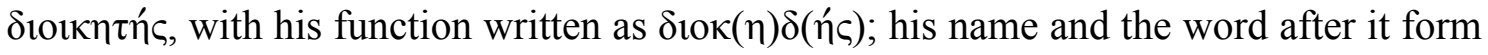
a heading, with the following entries set in. The interchange $\tau>\delta$ is frequent; as for $\delta$ iok- written instead of $\delta$ 1oเk-, there is a parallel to the omission of iota in the text on the other side. Every entry (after 1. 1) in the list on the front and most entries in the first column on the back begin onk $\mathrm{V}$, i.e., otkov (Wessely's transcription is slightly variable),

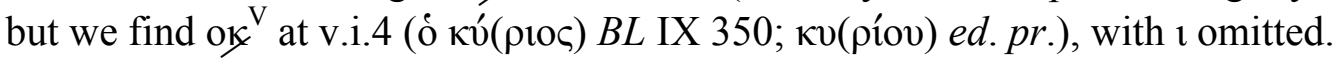

Apart from the last passage, oťkov was also not read in lines 5-6 and 8-9 of column $\mathrm{i}$ of the text on the back. In 1.5 , shown as entirely lost in the edition, read o[1] $x^{[\mathrm{V}]}$. In 1 . 6 , the papyrus has owk ${ }^{[\mathrm{V}]}$, not $\gamma \alpha\left(\mu \varepsilon \tau \eta^{\prime}\right)$. The edition indicates a lacuna at the beginning 
of 11. $8-9$, before $\delta(1 \alpha$ ), but this is false; there is also a line after 1.9 that was not transcribed. ${ }^{28}$ We have: $\left({ }^{29}\right)$

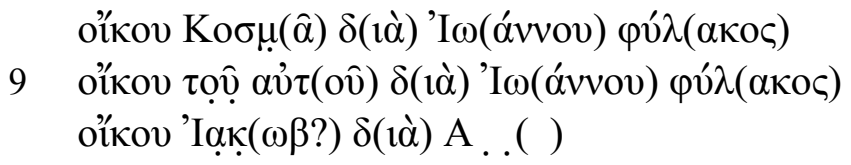

There are also some onomastic notabilia. The entry in 1.5 of the text on the front

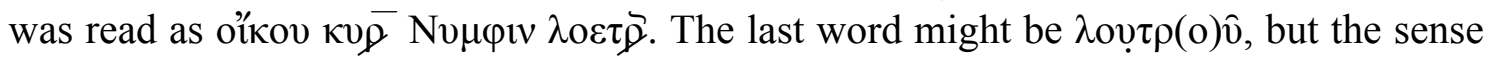

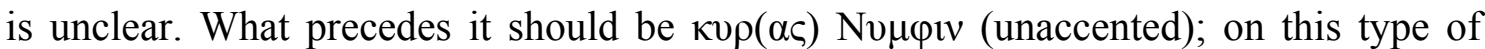
women's names, see J.-L. FouRnET \& J. GASCOU, ZPE 135 (2001) 146-9. $\left({ }^{30}\right)$ The next

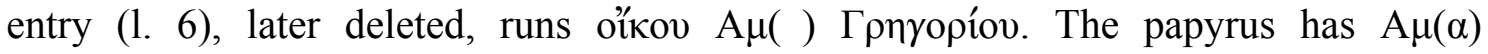

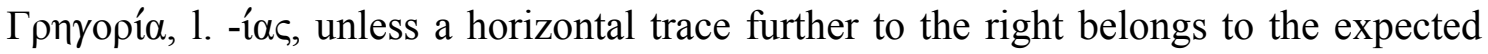

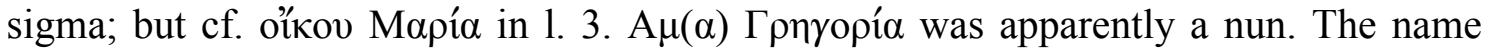
Грпүорí $\alpha$ does not seem to be otherwise attested in Egypt, and is generally rare.

\section{SPP XX 281}

Like most previous items, this is an Arsinoite tax register of the eighth century. Here too several corrections have been proposed, but there are still several difficulties.

In 1. 6, 'A $\beta 1 \alpha($ ) became 'A $\beta 1($ ) in $B L$ VIII 478; I propose to read 'A $\beta \rho(\alpha \alpha \mu$ íov), even if the putative rho has no circlet. The name of this person's father, $\Theta \varepsilon \circ \delta($ ), should probably read as $\Theta \varepsilon o \delta(\omega ́ \rho o v) .\left({ }^{31}\right)$ It is also possible that the first letter is delta, a common writing of this name; cf. e.g. CPR IV 126.1, 7 or XIX 29.1, 5, etc. $\left({ }^{32}\right)$ The same holds for $\Theta \varepsilon o \delta(\omega ́ \rho) v)$ in 11.12 and 15.

1.6

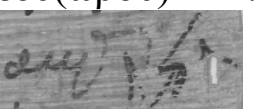

1.8

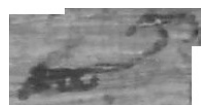

1. 11

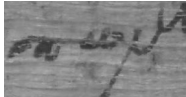

In 1. 8, we find 'A $\pi(\alpha)$ 'H $\mathrm{\lambda} i \mathrm{i}_{(\varsigma)}$. The abbreviated 'A $\pi(\alpha)$ gives difficulty; cf. above, no. 5, and see already $B L$ VIII 478, though the alternative mentioned there, viz. 'A $\pi \hat{\alpha}(\varsigma)$, is not viable). Furthermore, if that was the scribe's intention, the form of the abbreviation would be odd. Could it be that we have 'A $\pi \mathrm{o} \lambda(\lambda \hat{\omega})$ ?

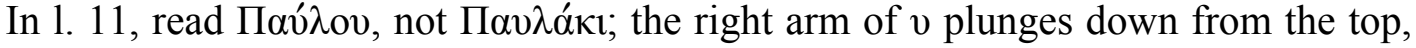
as often in this period.

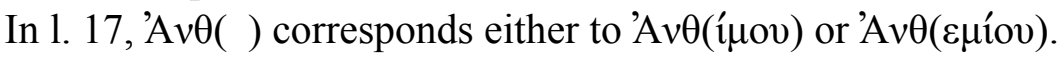

In 1. 24, the agnostic K( ) 'I $\omega$ ( ) should cede its place to Kọ( $\sigma \mu \hat{\alpha})$ ' $\mathrm{I} \omega(\alpha \dot{\alpha} v v o v)$; for the writing of $\operatorname{Ko}(\sigma \mu \hat{\alpha})$, cf. 1.25 , with $B L$ VIII 478 , and above, no. $13 . \mathrm{K}()$ in 1.7 is more difficult; if we read $\operatorname{Ko}(\sigma \mu \hat{\alpha})$, the high upright trace above the break, which does

(28) Another line that was not reported is the very last of col. iii on the back; see $B L$ IX 350 . All that can be read with certainty is the number at the end: $\beta$.

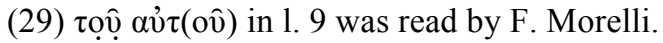

(30) The observation on the name in $S B 13762$ was first made by S. Slattery in his Oxford D.Phil. thesis of 2013.

(31) The name is followed by a sum of money, transcribed as $\delta^{\prime} \gamma \cdot \gamma \overline{\varsigma \kappa} \delta$ in ed. pr. $\left(\delta^{\prime} \gamma^{\prime} / \gamma^{\prime} \varsigma^{\prime} \kappa \delta^{\prime}\right.$ in $D D b D P) ; \operatorname{read} v o(\mu i ́ \sigma \mu \alpha \tau \alpha) \llbracket \delta \gamma^{\prime} \rrbracket \gamma \varsigma^{\prime} \kappa \delta^{\prime}$ (the first two figures are crossed out). The sigle for vo( $\left.\mu i^{\prime} \sigma \mu \alpha \tau \alpha\right)$ is a mere dot.

(32) Cf. also $S P P \times 40.15 \delta(i \grave{\alpha}) \Delta[.] \delta \omega \rho[$, where the papyrus seems to have $\delta \varepsilon \delta \omega \rho[$; read $\Delta \varepsilon<0>\delta \omega ́ \rho[o v ?$ 
not belong to the previous line, will be left unexplained. But it cannot be 'H $\lambda$ ía, the name written immediately before.

\section{7}
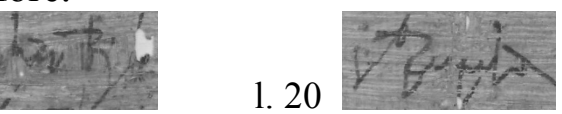

More uncertain is the entry in 1. 20, for which $B L$ VIII 478 produced $\Gamma$ (ov̂v) $\theta(\mathrm{oc})$

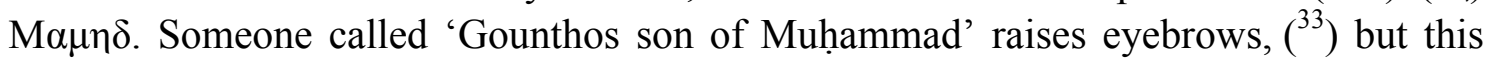

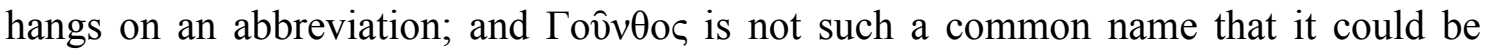
shortened in such a drastic way. Wessely had read $\gamma()$ with $\angle$ over it; the superscript letter is indeed $\theta$, but to my eyes what is written on the line looks like an elliptical $\delta: \delta /$, to be resolved as $\delta(\mathrm{o}) \theta(\mathrm{)})$. But this would be unique in this text.

There are a few other enigmatic names, two of which may be read differently. $\left({ }^{34}\right)$

1. 16

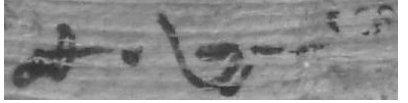

1. 18

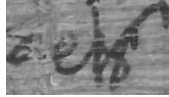

In 1. 16, Wessely read $\Sigma^{\theta}\left(\right.$ ) ov ${ }^{\omega}$; the latter word was changed to Ov $\tau \omega($ ) (BL VIII $478) . c^{\theta}=\Sigma(\varepsilon v o v) \theta($ loc) occurs in 11.12 and 17 of this text, but here the first latter is most probably $\alpha$. I do not know what to make of $A \theta o v \tau \omega($ ). It seems less likely that we

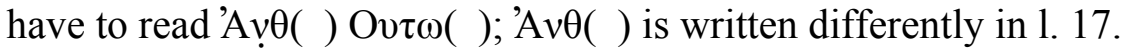

In 1. 18, Wessely's 'A $\rho \kappa^{\prime}$ has become 'Aркó $\tau($ ov) (BL VIII 478), but it would be

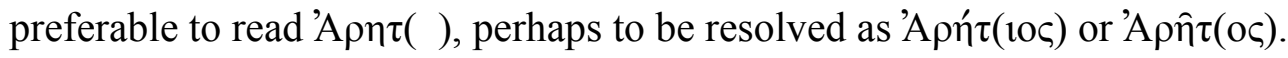

A note on the heading of the text is also in place. According to the edition, it began

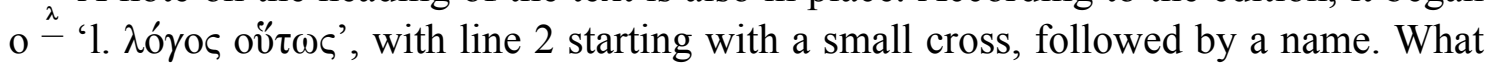
the scribe wrote is a second, taller cross with some ornamentation, somewhat reminiscent of the cross at the beginning of $C P R$ IV 126.1:

SPP XX 281.1

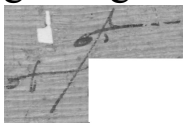

CPR IV 126.1

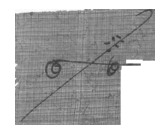

The current 1.2 should become 1. 1, etc.

University College London

Nikolaos GoNIS

(33) There is $\Sigma \dot{\prime} \mu(\omega v) \Sigma \varepsilon \eta \delta$ in 1. 22, but the first name is not abbreviated and may be something else.

(34) Both pointed out to me by F. Morelli. 